\title{
In situ transmission electron microscopy and spectroscopy studies of rechargeable batteries under dynamic operating conditions: A retrospective and perspective view
}

\author{
Chong-Min Wang ${ }^{\text {a) }}$ \\ Environmental Molecular Sciences Laboratory, Pacific Northwest National Laboratory, Richland, Washington 99354, USA
}

(Received 11 June 2014; accepted 12 August 2014)

\begin{abstract}
Since the advent of the transmission electron microscope (TEM), continuing efforts have been made to image material under native and reaction environments that typically involve liquids, gases, and external stimuli. With the advances of aberration-corrected TEM for improving the imaging resolution, steady progress has been made on developing methodologies that allow imaging under dynamic operating conditions, or in situ TEM imaging. The success of in situ TEM imaging is closely associated with advances in microfabrication techniques that enable manipulation of nanoscale objects around the objective lens of the TEM. This study summarizes and highlights recent progress involving in situ TEM studies of energy storage materials, especially rechargeable batteries. The study is organized to cover both the in situ TEM techniques and the scientific discoveries made possible by in situ TEM imaging.
\end{abstract}

\section{INTRODUCTION}

Over the last decade, tremendous progress has been made on the development of aberration-corrected scanning/transmission electron microscopy (S/TEM). ${ }^{1-8}$ As a result, atomic-scale imaging and spectroscopic probing of materials appear to be routine practice. $^{9-14}$ Imaging materials at or near-realistic working conditions, or in situ S/TEM, is keeping pace with the progress of high-spatial, fast-temporal, and high-energy resolution, as exemplified by the in situ TEM observation of nanostructured materials growth, ${ }^{15,16}$ the solid-gas reaction in a catalytic system, ${ }^{17-19}$ materials deformation behavior, ${ }^{20,21}$ particle nucleation and growth from a solution, ${ }^{22-24}$ the electrochemical deposition process, ${ }^{25}$ and cells in a liquid environment. ${ }^{26}$ This progress has benefited from both the development of a dedicated microscope that can handle certain gas pressure around the sample region, such as the environmental TEM, and the ability to manipulate and microfabricate materials at the nanoscale.

Energy storage technologies, such as lithium-ion (Li-ion) batteries, now are indispensably used for portable electronics, electric vehicles, and renewable energies. ${ }^{27-31}$ One of the fundamental challenges for battery research is direct observation of the structural and chemical evolution of the battery components and how this directly correlates with battery properties.

\footnotetext{
a) Address all correspondence to this author.

e-mail: Chongmin.Wang@pnnl.gov

DOI: $10.1557 /$ jmr.2014.281
}

The ex situ method, based on electron beam imaging and spectroscopy, has been widely used for probing the structural features of a lithium battery system. ${ }^{32-39}$ However, due to the dynamic nature of the process, the ex situ method cannot answer some of the questions related to the dynamic process during battery operation. ${ }^{35,40-43}$ For example, $\mathrm{LiCoO}_{2}$ has been used successfully as a cathode material for Li-ion batteries, and ex situ TEM studies indicate that there are high-density dislocations in the $\mathrm{LiCoO}_{2}$ electrode. ${ }^{44}$ This observation subsequently raises several fundamental questions, such as when and how are these dislocations generated? What role do dislocations play during battery operation? And, what is the role of these dislocations on the growth of the solid electrolyte interface (SEI) layer? Answers to these questions only can be obtained by making measurements under operating conditions, such as in situ observation in a TEM. In particular, experiments must be designed to "observe" the dynamic evolution of the interface and internal structure of electrode during operation of the battery in a TEM and, ultimately, ${ }^{35,45}$ to seek atomic and nanoscale understanding of the mechanisms associated with the following: (1) nature of the SEI layer between the electrode and the electrolyte, along with the movement of the SEI layer inside the electrode during charging/discharging ${ }^{42,43,46}$; (2) change in the composition/structure of the SEI layer, along with the orientation/morphology of the nanostructured electrodes ${ }^{35,36}$; and (3) Li-ion insertion and extraction mechanisms during the electrochemical cell's operation. $^{33,34,47,48}$ 


\section{CHALLENGES FOR IN SITU TEM IMAGING OF A RECHARGEABLE BATTERY}

Electrochemical energy storage devices are complex, multicomponent systems that incorporate widely dissimilar phases in physical and electrical contact. ${ }^{30,43,46}$ Operation of a rechargeable battery relies critically on electron and ionic transfer across the solid-solid and solid-liquid interfaces and within each of the constituent phases. Repeated charging and discharging of the battery induces microstructural evolutions both at the interface between the electrolyte and electrode and within the electrode (active materials) due to ionic migration. Although it has been established that this structural evolution of active materials is responsible for battery failure, the mechanisms of the microstructural evolutions as a function of charging/discharging are not well understood. ${ }^{30,46}$ Overall, this imposes a fundamental scientific question regarding how the microstructures within the constituent materials and across the interface/interphase confined by the constituents evolve and affect the consequence of this structural evolution on cell properties. Due to the possibility of directly monitoring dynamic processes, in situ methods based on spectroscopies, ${ }^{35,42,43,45,46}$ atomic force microscopy (AFM), ${ }^{43,49}$ and SEM imaging ${ }^{50,51}$ have provided useful information regarding the structural evolution of the electrode materials during a battery's operation. ${ }^{49,52-60}$ Because of the TEM's high-vacuum operation and the vacuum incompatibility of liquid electrolyte used for most rechargeable batteries, including the Li-ion battery, the fundamental challenge is the integration of the liquid electrolyte and electrode system in the TEM's highvacuum column.

\section{IN SITU TEM STUDY OF RECHARGEABLE BATTERIES}

Three strategies have been explored for this in situ TEM study of batteries, including open-cell configuration, closed liquid-cell configuration, and a whole solid-state battery.

\section{A. Open-cell configuration using ionic liquid- based electrolyte}

Over the last few years, substantial progress has been made toward developing methodologies for in situ direct observation of structural and chemical evolution of electrodes used for Li-ion batteries ${ }^{49,53,54,60-69}$-most notably, the development of an in situ TEM cell based on an open-cell configuration. The fundamental concept of the open-cell configuration for in situ TEM studies of the Li-ion battery was pioneered by Wang et al. ${ }^{53}$ and Huang et al. ${ }^{60}$ The basic operating principle of the cell is schematically illustrated in Fig. 1, where
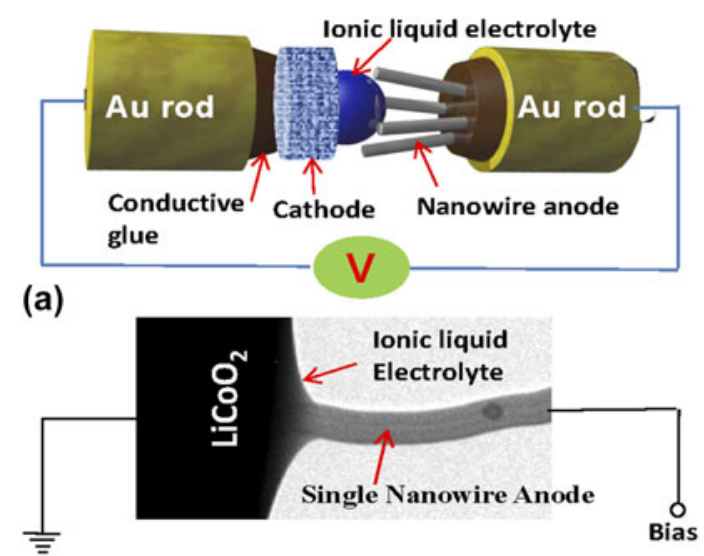

(b)

FIG. 1. (a) Schematic drawing showing the experimental setup of the open-cell approach using ionic liquid as the electrolyte, (b) TEM image showing a working nanobattery in TEM column, where the single nanowire anode can be imaged during charge and discharge of this nanobattery.

the ionic liquid was used as an electrolyte..$^{40,53,60,63}$ The essential components of the cell are a single nanowire as the observable electrode, vacuum-compatible ionic liquid as the electrolyte, and $\mathrm{LiCoO}_{2}$ as the counter electrode. A typical ionic liquid electrolyte is lithium bis(trifluoromethanesulfonyl)imide (LiTFSI) dissolved in a hydrophobic ionic liquid 1-butyl-1-methylpyrrolidium $\left(\mathrm{P}_{14}\right)$ TFSI $\left(\mathrm{P}_{14}\right.$ TFSI). The overall composition of the electrolyte is $10 \%$ LiTFSI in $\mathrm{P}_{14}$ TFSI. The open-cell configuration offers the possibility of atomic-level spatial resolution and analytical capability to study Li-ion insertion mechanisms into electrode materials during the charge/discharge cycles. ${ }^{65,70-73}$ Since its invention, this technique has helped to reveal many details with respect to the lithiation mechanisms and structural evolution behavior of a range of materials, especially anode materials including $\mathrm{Si}^{61-65,70,73,74} \mathrm{Ge},{ }^{75}$ $\mathrm{Al}_{2} \mathrm{O}_{3},{ }^{76} \mathrm{SnO}_{2},{ }^{54,60,72,77,78} \mathrm{ZnO},{ }^{79}$ graphene, ${ }^{80} \mathrm{Sn},{ }^{81}$ and carbon nanotubes. ${ }^{82}$ It has been noticed that the ionic liquid will spread along the nanowire surface to form a thin layer of coating. Therefore, this configuration can, in some degree, mimic the real battery configuration such that the liquid electrolyte forms a conformal coating around the active component in the electrode. The drawback of this method is the polymerization of the ionic liquid electrolyte under the imaging electron beam. As such, the cell only can be cycled several times, which is far short for revealing the structural evolution of the electrode materials relevant to a real battery.

\section{B. Open-cell configuration based on Li metal and metal oxide as the electrolyte}

A variation of the open-cell configuration based on an ionic electrolyte (previously described) is the open-cell 
configuration using lithium oxide as the electrolyte. In this configuration, a Li metal is used as the anode, and a single nanowire is used as the cathode (shown schematically in Fig. 2). During insertion of the TEM holder into the TEM column, the Li metal surface is instantaneously oxidized to form a thin layer of $\mathrm{Li}_{2} \mathrm{O}$, covering the surface of the Li metal. It is this layer of $\mathrm{Li}_{2} \mathrm{O}$ that serves as a solid electrolyte. ${ }^{67,83,84} \mathrm{In}$ a typical example, a $\mathrm{Si}$ nanowire is used as one electrode, $\mathrm{Li}_{2} \mathrm{O}$ on Li metal is the solid electrolyte, and a bulk Li metal is the counter electrode. In principle, the battery assembled in this way is a charged battery, and connecting the circuit will lead to the discharging process. However, this will not be the case due to the low conductivity of the $\mathrm{Li}$ ion in $\mathrm{Li}_{2} \mathrm{O}$ at room temperature. ${ }^{83} \mathrm{~A}$ negative potential of typically $2-4 \mathrm{~V}$ normally is applied between $\mathrm{Si}$ and $\mathrm{Li}$ to drive $\mathrm{Li}$ ions into $\mathrm{Si}$. The propagation of the lithiation front can be clearly visualized by TEM imaging. The open-cell configuration offers the advantage of high spatial resolution imaging and chemical composition analysis by spectroscopic method. In a typical example, Fig. 3 shows the measured lithiation length of $\mathrm{Si}$ as a function of lithiation time, illustrating near-parabolic lithiation behavior. Simultaneously, the chemical composition evolution can be mapped using electron energy loss spectroscopy, or EELS. ${ }^{63,64}$ The silicon map is obtained by an integration of $\mathrm{Si} L$ edges (99-170 eV), and the $\mathrm{Li}$ map is acquired by an integration of Li $K$ edges (55-85 eV) after background subtractions. Notably, this type of experiment is not a real rechargeable battery. However, the structural response of $\mathrm{Si}$ with the Li-ion insertion adequately simulates what

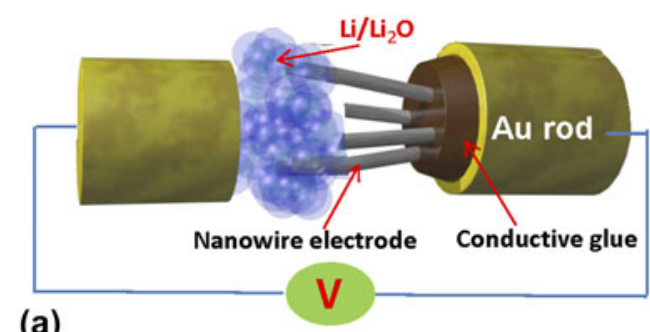

(a)

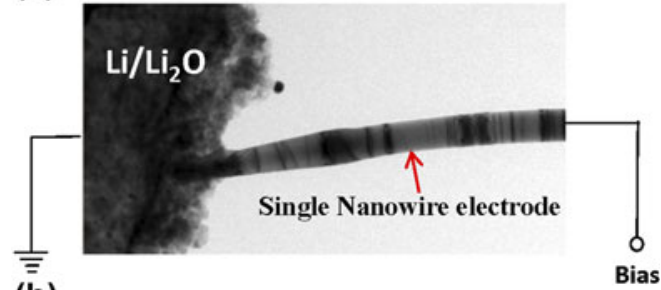

(b)

FIG. 2. (a) Schematic drawing showing the experimental setup of the open-cell approach using $\mathrm{Li}$ metal as the lithium source and $\mathrm{Li}_{2} \mathrm{O}$ as the solid electrolyte, (b) TEM image of a nanobattery with a single nanowire as cathode, which allows the direct observation of the structural and chemical evolution during charge and discharge. happens in a real battery. Therefore, this open-cell configuration provides a quick and convenient way for probing the intrinsic response of material to Li-ion insertion or extraction. A similar principle can be used with other metallic ion systems for studying ionic insertion and extraction behavior, such as in $\mathrm{Na}-, \mathrm{Mg}-$, and $\mathrm{Ca}-\mathrm{ion}$ batteries. ${ }^{84}$ Another variation of the open-cell configuration has been developed by others using a standard TEM grid as described by Wang et al. ${ }^{66}$ The advantage of using a TEM grid is that it can increase the system's stability, affording high spatial resolution imaging.

\section{The closed electrochemical liquid-cell for direct correlation of structure and electrochemical properties}

In situ TEM work conducted on open-cell configurations has provided insightful information on the structural and chemical evolution of electrodes upon lithiation/delithiation. However, three typical deficiencies are associated with the open-cell configuration. First, for the open-cell, the electrolyte is only in point contact with the electrode, which may inadvertently modify the diffusion pattern of the $\mathrm{Li}$ ion in the electrode. Therefore, what has been observed is not necessarily a representative case for the electrode being fully immersed in the liquid electrolyte in a real battery. Second, in using $\mathrm{Li}_{2} \mathrm{O}$ as the electrolyte, a large overpotential is normally applied to drive the $\mathrm{Li}$ ions into the electrode, which may change the kinetics and phase behaviors of solid-state electrode lithiation. Third, using the ionic liquid or $\mathrm{Li}_{2} \mathrm{O}$ electrolyte excludes some of the fundamental processes that occur only in real electrolytes and battery-operating conditions, such as the interaction between the electrolyte and electrode and the SEI layer formation.

To address the shortcomings of the open-cell (already described), recent work has focused heavily on developing a liquid-cell for in situ or more precisely operando TEM studies of Li-ion batteries using a battery-relevant liquid electrolyte and a lithium metal counter electrode. The in situ TEM study of electrochemical processes was initiated following the work depositing copper nanoparticles from a $\mathrm{CuSO}_{4}$ electrolyte under galvanostatic conditions using a liquid-cell into the TEM column. ${ }^{25}$ Since then, the microfabricated liquid-cell concept has inspired rapid development of in situ TEM imaging under liquid or gas environments for which most of the studies have focused on nucleation and growth of nanoparticles, a process that is essentially stimulated by the imaging electron beam. ${ }^{22,23,85-90}$ The progression of liquid-cell microscopy, in turn, has helped push the development of an electrochemical cell process. ${ }^{91,92,93}$ This approach already has allowed direct observation of beam-sensitive systems, such as macromolecular complexes ${ }^{93,94}$ and soft 
(a)

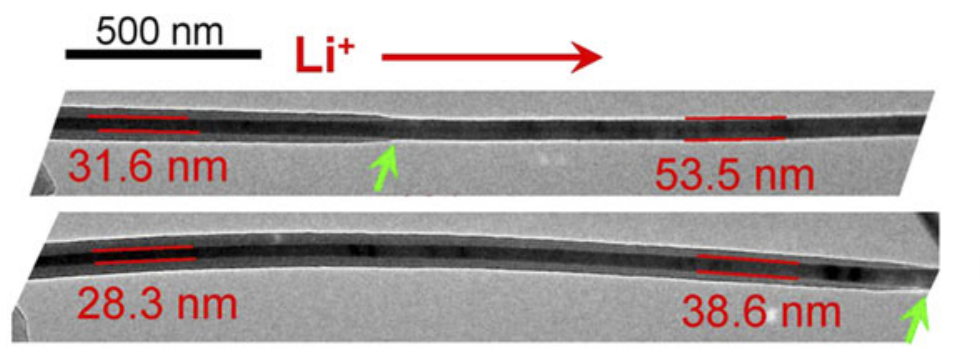

$0 \mathrm{~s}$

(b)
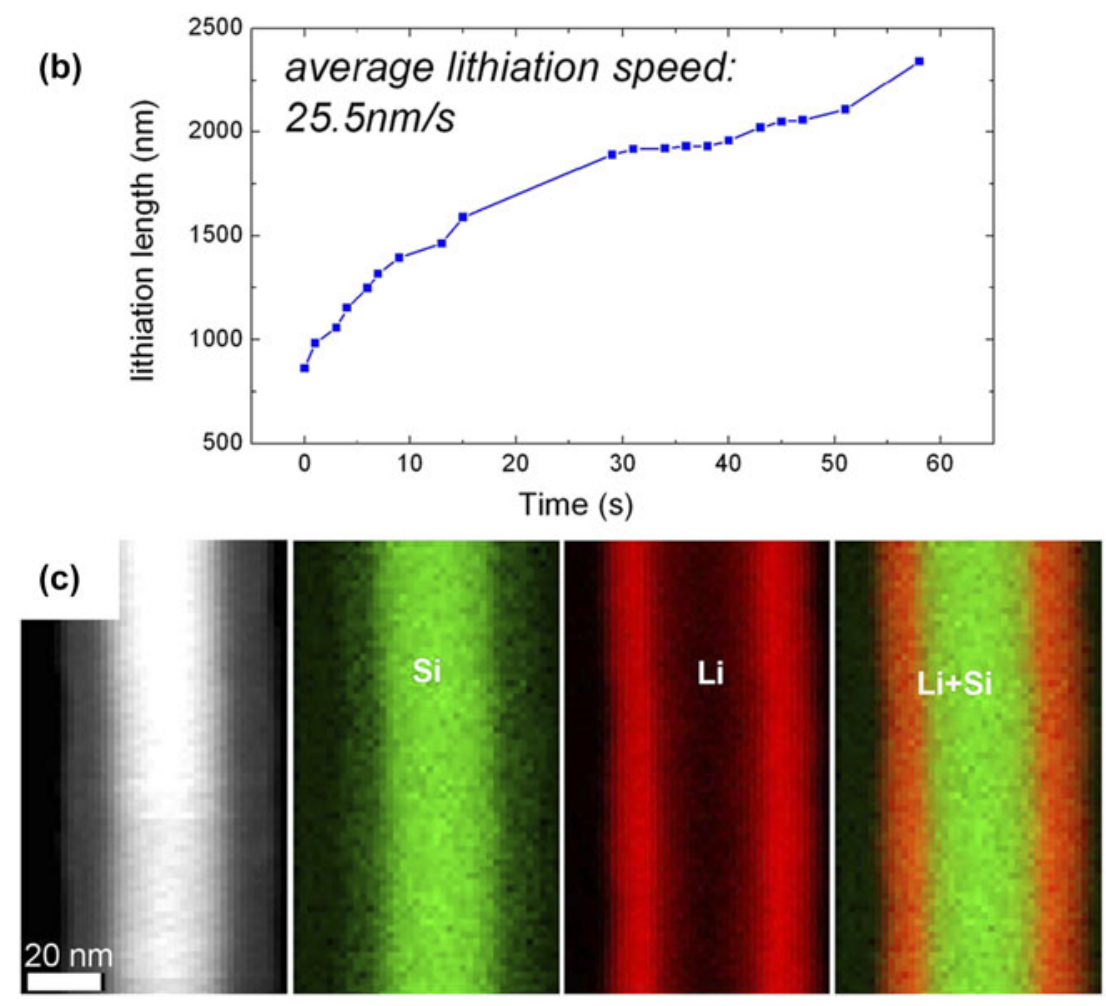

FIG. 3. The lithiation process observed using an open-cell configuration for Si. (a) Progression of lithiation of Si in a core-shell fashion. (b) Measured lithiation length as a function of time. The average lithiation speed is $\sim 25.5 \mathrm{~nm} / \mathrm{s}$. In (a), the $\mathrm{Li}^{+}$diffusion direction is labeled by the red arrows, and the lithiation reaction fronts are marked by green arrows. The electron dose is $1.55 \mathrm{~A} / \mathrm{m}^{2}$. (c) STEM-high-angle annular dark-field (HAADF) image and EELS mapping of $\mathrm{Si}, \mathrm{Li}$, and overlaid $\mathrm{Si}$ and $\mathrm{Li}$ composite, revealing a core-shell lithiation.

materials, ${ }^{95,96}$ and of processes that span from electrochemical deposition of metals ${ }^{25,97}$ to growth of different nanostructures. ${ }^{23,86,88,89,98,99}$

$\mathrm{Gu}$ et al. ${ }^{100}$ successfully demonstrated the first working closed liquid-cell for a rechargeable battery (schematically illustrated in Fig. 4). Subsequently, similar devices have been demonstrated by other groups as well. ${ }^{100-104}$ In a typical example, the working electrode is a single $\mathrm{Si}$ nanowire, while the counter electrode is a Li metal. This electrode geometry was implemented using a $\mathrm{SiN}_{x}$ membrane deposited on $\mathrm{Si}$ chips (illustrated in Fig. 4). An $\sim 50 \mathrm{~nm}$-thick $\mathrm{SiN}_{x}$ membrane is used to seal the liquid while still allowing transmission of the highenergy electrons for imaging. The biasing chip has six Pt electrodes. The Pt electrodes extend from the $\mathrm{SiN}_{x}$ window to the edge of the chip, connecting the electrode to the outside circuit. A single or multiple Si nanowires can be mounted on one of the Pt electrodes using focused ion beam (FIB) manipulation and Pt deposition welding. The welded Si NWs extend to the electron-transparent $\mathrm{SiN}_{x}$ membrane region to enable imaging of the nanowire in electron transmission mode. A droplet of $1.0 \mathrm{M}$ of lithium perchlorate, $\mathrm{LiClO}_{4}$ - containing mixed ethylene carbonate (EC) and dimethyl carbonate (DMC) electrolytes $(3: 7, \mathrm{v} / \mathrm{v})$ - was applied to the top surface of the $\mathrm{SiN}_{x}$ membrane (fully immersing all Pt electrodes, Li metal, and $\mathrm{Si}$ NWs), and a blank chip with a $\mathrm{SiN}_{x}$ membrane facing down was placed over the biasing chip to seal the liquid electrolyte. The sealing is completed based on a three-O-ring technique, and the whole device is implanted on a biasing in situ TEM liquid holder (Hummingbird Scientific, Lacey, WA). The assembly 
(a)

\section{$\mathbf{e}^{-}$beam}

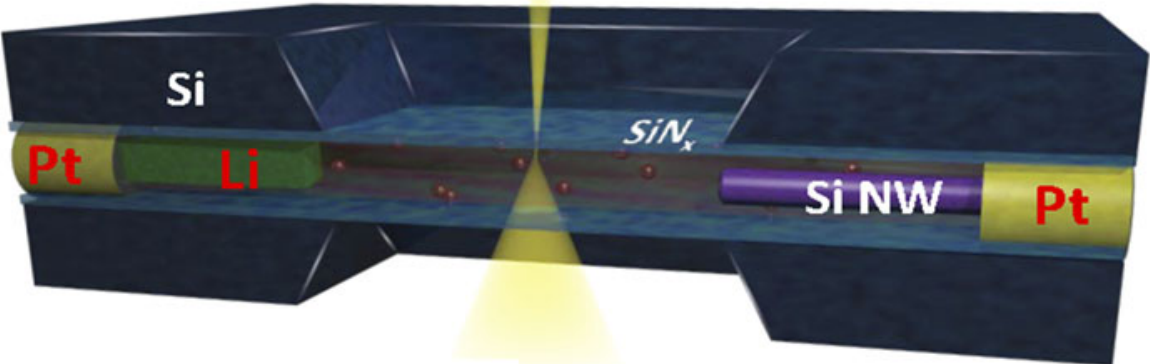

(b)

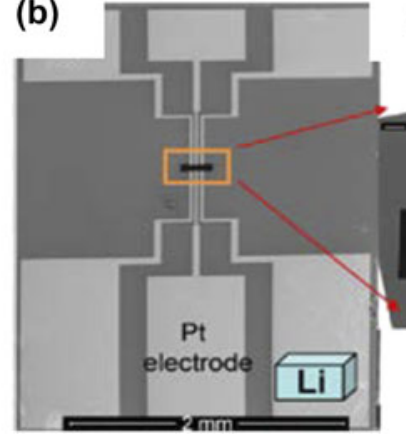

(c)

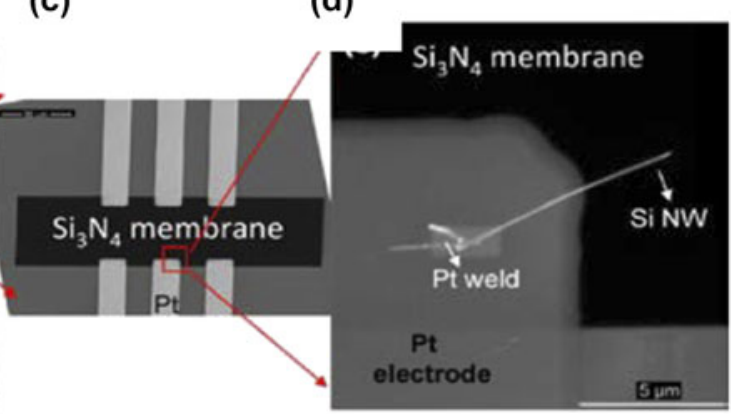

FIG. 4. (a) Schematic drawing showing the setup of the liquid-cell battery. (b) SEM image of the inner side of the biasing chip, (c) magnified view of the region labeled by the orange rectangle, and (d) SEM image showing the welded Si NW electrode onto the Pt contact. Note that the Li location is labeled by the light blue color object in panel (based on the TEM holder system developed by Hummingbird Scientific).

process was completed in an argon-filled glove box to avoid atmospheric degradation of the electrolyte/electrodes. The viewing window dimensions are $50 \mu \mathrm{m} \times 50 \mu \mathrm{m}$. The normal thickness of liquid layer is $500-1000 \mathrm{~nm}$. However, after loading the cell into the TEM column, the membrane will bulge outward due to the pressure differences.

\section{Direct in situ TEM observation of lithiation/delithiation of $\mathrm{Si}$, $\mathrm{Li}$ ion transport in $\mathrm{LiFePO}_{4}$, and SEI layer formation on an Au electrode}

The lithiation of $\mathrm{Cu}$-coated crystalline $\mathrm{Si} \mathrm{NW}$ in the liquid-cell is performed by holding the voltage of the $\mathrm{Cu}-\mathrm{Si}$ anode to $\sim 0.03 \mathrm{~V}$ range. The structural evolution of the nanowire upon lithiation is illustrated by the captured video frames shown in Figs. 5(a) and 5(b). The lithiation of the $\mathrm{Si}$ nanowire immersed in the liquid electrolyte progresses in the core-shell fashion. The total diameter of the wire changes from $100 \mathrm{~nm}$ to $391 \mathrm{~nm}$ at $2462 \mathrm{~s}$. Based on the projected radial dimension increase, this indicates that the radial direction of this wire is along the $\langle 110\rangle$ direction (maximum volume expansion direction of Si upon lithiation). ${ }^{41,73}$ The increase in the diameter is quicker at the beginning of lithiation and slows down with progression of the lithiation process. This phenomenon is related to the interface stress generated by the volume expansion, which limits the diffusion of $\mathrm{Li}$ ions further into the core. The slowdown of lithiation after partial lithiation also has been consistently reported by earlier researchers. ${ }^{61,71,105}$

The delithiation process of a pure Si nanowire is shown in Figs. 5(d)-5(f). The delithiation process is performed by scanning the voltage from 0 to $0.65 \mathrm{~V}$ at an increment of $0.3 \mathrm{mV} / \mathrm{s}$, and the current versus voltage curve is plotted in Fig. 5(c). The image shown in Figs. 5(d)-5(f) represents a pair of dark-field (left) and bright-field (right) STEM images. In Fig. 5(d), the white arrows in the dark-field image indicate the Pt markers, which were intentionally deposited on the nanowire using electron beam deposition in the FIB SEM. The Pt markers show a higher $Z$-contrast in the dark-field images, highlighting the wire's positions in the liquid-cell. The diameter of the lithiated Si nanowire is $195 \mathrm{~nm}$ [shown in Fig. 5(d)]. The diameter of the nanowire shrank when the voltage scanned to $0.45 \mathrm{~V}$, as shown in Fig. 5(e). The diameter kept decreasing as lithium ions were extracted. In the end, the diameter shrank to $\sim 92 \mathrm{~nm}$ in the final delithiated state, as shown in Fig. 5(f) at $0.65 \mathrm{~V}$. The large volume change, as measured based on the reduction in diameter from 195 to $92 \mathrm{~nm}$, indicates that most of the $\mathrm{Li}$ ions were extracted during this process.

Using a closed liquid-cell configuration, Holtz et al. ${ }^{101}$ studied the Li-ion transport kinetics and degradation mechanisms in $\mathrm{LiFePO}_{4}$ particles during the charge/discharge cycles. Observations of Li transport 

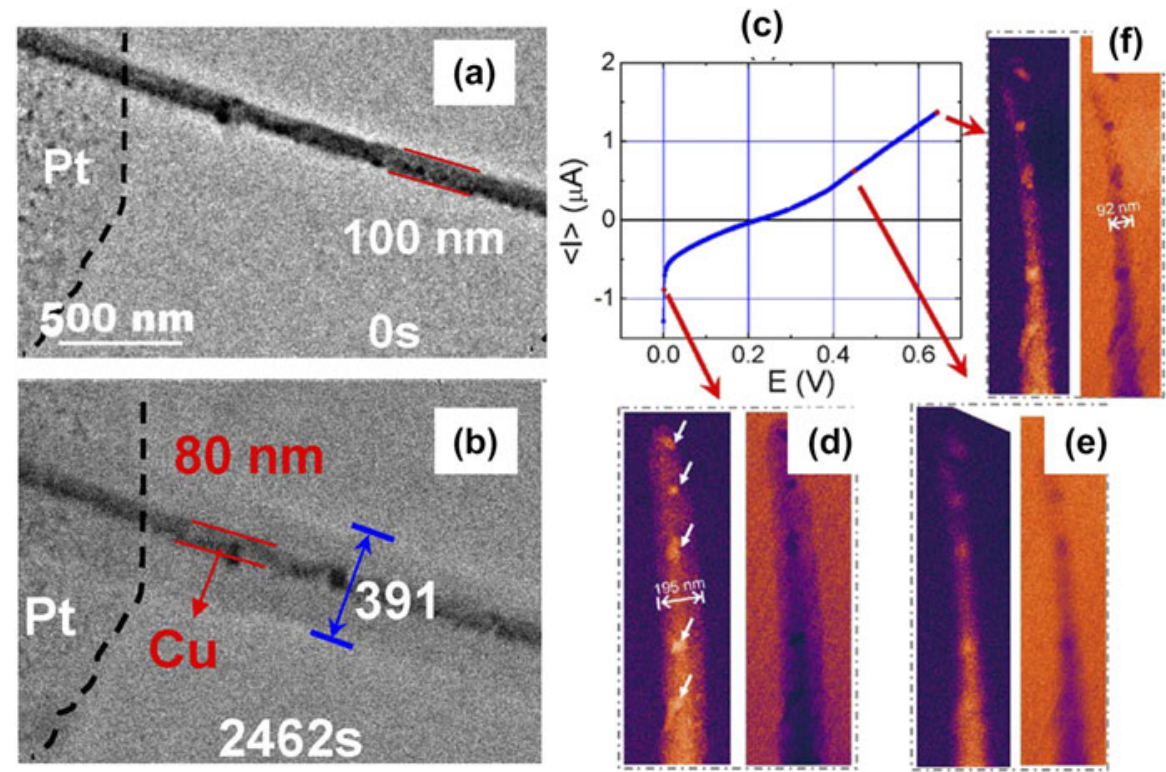

FIG. 5. In situ liquid-cell TEM observation of the lithiation of $\mathrm{Cu}$-coated $\mathrm{Si}(\mathrm{Cu}-\mathrm{Si}) \mathrm{NW}$. (a) TEM image showing the pristine state of the $\mathrm{Cu}-\mathrm{Si}$ $\mathrm{NW}$ at $0 \mathrm{~s}$, and (b) core-shell formation of the $\mathrm{Cu}-\mathrm{Si} \mathrm{NW}$ during lithiation at $2462 \mathrm{~s}$. (c) Current versus voltage plot during the delithiation process. (d-f) STEM Z-contrast image and bright-field images of the nanowire at different states of delithiation (the left side of each panel in (d-f) shows the HAADF Z-contrast image, and the right side shows the corresponding bright-field STEM image acquired simultaneously). Note that the white arrows in (d) indicate the deposited Pt markers for Ref. 100.

are very challenging. However, in their experiment, they used energy-filtered TEM imaging by selecting a valence energy loss peak at $5 \mathrm{eV}$, which is unique for $\mathrm{FePO}_{4}$ but not for $\mathrm{LiFePO}_{4}$. Therefore, environmental transmission electron microscopy (ETEM) images captured with the energy window selected at this region can be used to probe the phase transition and $\mathrm{Li}$ transport characteristics between $\mathrm{LiFePO}_{4}$ and $\mathrm{FePO}_{4}$. This method allowed Holtz et al. ${ }^{101}$ to determine the lithiation state of a $\mathrm{LiFePO}_{4}$ electrode and surrounding aqueous electrolyte in real time with nanoscale resolution during electrochemical charge and discharge, enabling them to track lithium transfer between the electrode and electrolyte and image charging dynamics in the cathode.

Zeng et al. ${ }^{103}$ reported the formation of the SEI layer on an $\mathrm{Au}$ electrode during electrochemical lithiation and delithiation of $\mathrm{Au}$ anodes in lithium hexafluorophosphate $\left(\mathrm{LiPF}_{6}\right) / \mathrm{EC} /$ diethyl carbonate (DEC) electrolyte. Upon the cyclic voltammetry (CV) scan, they noticed the inhomogeneous lithiation of the $\mathrm{Au}$ electrode, lithium metal dendritic growth, electrolyte decomposition, and SEI formation. The SEI layer growth appears to be concurrently accompanied by the $\mathrm{Li}$ dendrite growth. The SEI layer is observed to uniformly develop on the $\mathrm{Au}$ electrode surface. In a similar effort, Sacci et al. ${ }^{102}$ observed the SEI layer on an $\mathrm{Au}$ electrode in $1.2 \mathrm{M}$ $\mathrm{LiPF}_{6} \mathrm{EC}_{\mathrm{DMC}}$ battery-grade electrolyte. They noticed that SEI formed prior to the deposition of Li. Most dramatically, they found that the SEI layer shows a feature of dendritic morphology rather than a uniform layer: the dendritic SEI forms prior to Li deposition, and the SEI layer remains on the surface after $\mathrm{Li}$ electrodissolution. Therefore, the formation of SEI dendrites begins prior to Li deposition, suggesting that the electrolyte composition (and its electrodecomposition) affects $\mathrm{Li}$ deposition. It should be noted that for the case of the SEI layer growth work, no $\mathrm{Li}$ source is supplied in the liquid-cell. All observed phenomena result from the decomposition and deposition of the ions from the electrolyte. Even if a CV scan is done to offer a general view of the system's electrochemical behavior, more systematic work must be carried out with a proper $\mathrm{Li}$ source and a reference electrode.

\section{E. Solid-state battery configuration}

The solid-state battery configuration using a solid electrolyte provides another option to probe the structural and chemical evolution of electrode materials. For the solid-state configuration, it may be related to the solidstate system as a battery itself or as a platform for in situ TEM studies of a battery system. ${ }^{53,68}$ Brazier et al. $^{49}$ developed the first cross-section for an all-solid-state Li-ion nanobattery for in situ TEM observation (illustrated in Fig. 6). The fundamental concept of this configuration is to use FIB to make a "nanobattery" from an all-solid-state battery prepared by pulsed laser deposition (PLD). Using a similar configuration, Yamamoto et al. ${ }^{52}$ observed changes of electric potential in an all-solid-state Li-ion battery in situ with electron 


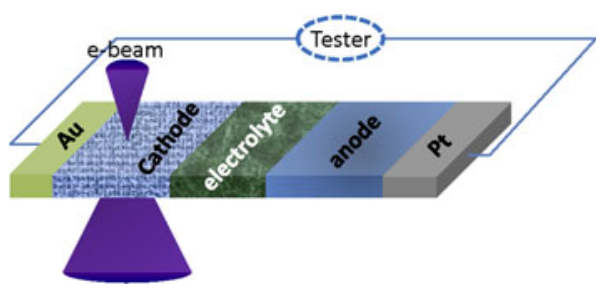

FIG. 6. Schematic drawing showing an all-solid-state battery machined by the FIB lift-out procedure for in situ TEM study.

holography (EH). They mapped the two-dimensional potential distribution resulting from movement of lithium ions near the positive-electrode/electrolyte interface. Meng et al. ${ }^{68}$ probed the dynamic phenomena in an all-solid-state nanobattery based on imaging and EELS. The solid-state configuration offers the possibility of high spatial resolution imaging. However, due to the rigidness of the nanobattery configuration, it is difficult to maneuver the sample to the appropriate orientation for lattice resolution imaging. A similar configuration based on a solid-state electrolyte and a single nanowire electrode also has been attempted. ${ }^{69,106}$ Overall, the solid-state battery configuration provides a platform for coupled imaging, diffraction, and spectroscopy for comprehensive structural and chemical analysis of nanobatteries under battery-operating conditions. In particular, tracking the Li may be possible via developed Li $K$-edge spectroscopy and mapping.

\section{F. Quasi-in situ TEM study of battery process}

The in situ TEM cell based on the open-cell, closed liquid-cell, and all-solid-state cell is an especially useful way to probe Li-ion transport and directly visualize the structural evolution of electrode materials. However, the nanobattery only can be cycled in situ in the TEM column for a very limited number of cycles, typically only up to 10 cycles. Thus, this type of in situ nanobattery lacks a direct correlation with electrochemical data for a large number of cycles. To address these issues, a quasi-in situ TEM observation of energy materials has been reported by Lin et al. ${ }^{107}$ The fundamental concept is to load the material of interest on a standard TEM grid that is embedded into the button cell with another battery material to perform a standard electrochemical testing. Following the electrochemical testing, the TEM grid is removed and loaded into a TEM for direct observation. This experimental scheme is mostly suited for probing the structural and chemical evolution of the electrode materials, but it is not suitable for probing the SEI layers due to the inevitable exposure of the sample in air following electrochemical testing. In principle, this appears to be a type of ex situ experiment. However, it provides the advantage of observing the same particle before and after electrochemical testing, as long as the particle is appropriately observed and marked.

\section{G. Electron-beam-induced effect in the open-cell}

As with all imaging situations, one issue for the open-cell in situ TEM study of lithiation is the electronbeam-induced effect. For electrochemical experiments, in addition to the generally observed beam effect such as knock-on damage, heating, and ionization of the materials, the electron beam also will affect the electrochemical process. It has been observed that the electron beam can either accelerate or retard the lithiation process, depending on the materials and electron dose. With uniform illumination of the whole nanowire by the electron beam, the beam effect cannot be visualized, yielding a uniform core-shell structure with silicon crystalline core and $\mathrm{Li}_{x} \mathrm{Si}$ amorphous shell (as shown in Fig. 3). The electron-beam-induced retardation of lithiation is vividly demonstrated by the lithiation of Si nanowires, as illustrated in Fig. 7. To identify the beam effect, the electron beam was focused on part of the nanowire with a dose of $22.3 \mathrm{~A} / \mathrm{m}^{2}$ (shown in Fig. 7). The region illuminated by the electron beam is marked by red arrows. The silicon core at the region under electron beam irradiation is lithiated at a slower rate than the region without electron beam exposure. Typically, the diameter of the silicon core in the region exposed to the electron beam is $37.6 \mathrm{~nm}$ compared to $26.9 \mathrm{~nm}$ in the region without the electron beam. Clearly, the electron beam inhibits the lithiation process.

The electron beam inhibition of lithiation appears to be consistent with the effect of electron-beam-induced delithiation of amorphous $\mathrm{Li}_{x} \mathrm{Si}$, as illustrated in Figs. 7(c)-7(e). The lithiated Si NW exhibits a Si crystalline core and amorphous $\mathrm{Li}_{x} \mathrm{Si}$-shell with a total diameter of $\sim 132 \mathrm{~nm}$. After irradiating the lithiated Si NW for $\sim 26$ min with an electron dose of $0.9 \mathrm{~A} / \mathrm{m}^{2}$, a delithiation process was noticed. Li metal formed on the surface of Si NW, and the diameter of the Si NW shrank to $\sim 82 \mathrm{~nm}$, as shown in Figs. 7(c)-7(e). A higher magnification TEM image in Fig. 7(c) clearly revealed that the formed Li metal exhibit crystalline contrast and some even with good surface facets. The EELS composition analysis, shown as the inset of Fig. 7(c), illustrates the $\mathrm{Li} K$ edges from the formed $\mathrm{Li}$ metal on the surface. It has been noticed that in the case of extremely high electron doses, the delithiation process happens without the formation of $\mathrm{Li}$ metal. This is due to the displacement damage of Li metal by the high-flux electron beam. Electron beams with a lower acceleration voltage, such as $80 \mathrm{kV}$, yield even higher damage to the lithiated $\mathrm{Li}_{x} \mathrm{Si}$ layer. Wang et al. ${ }^{108}$ calculated the displacement cross section of $\mathrm{Li}$ and $\mathrm{Li}$-containing compounds and concluded that electrons at lower acceleration voltage (even $60 \mathrm{kV}$ ) cause even more damage than at higher acceleration 

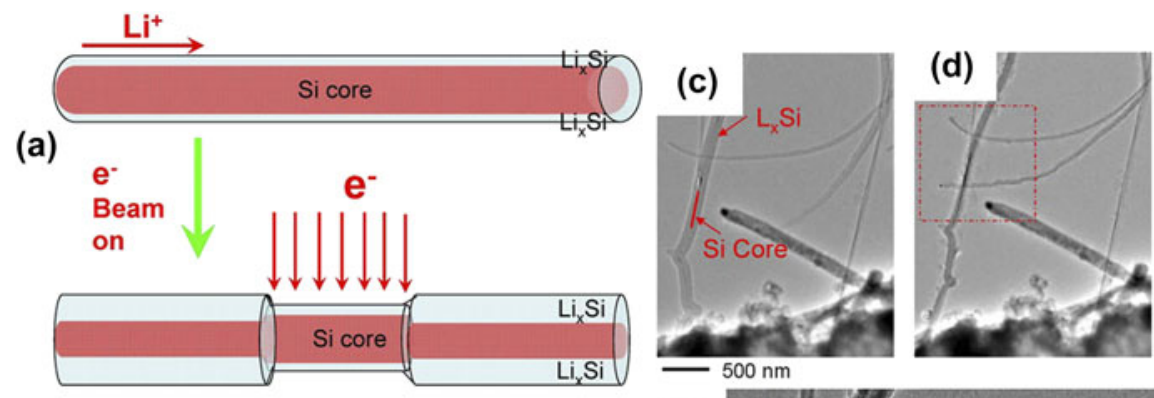

(b)
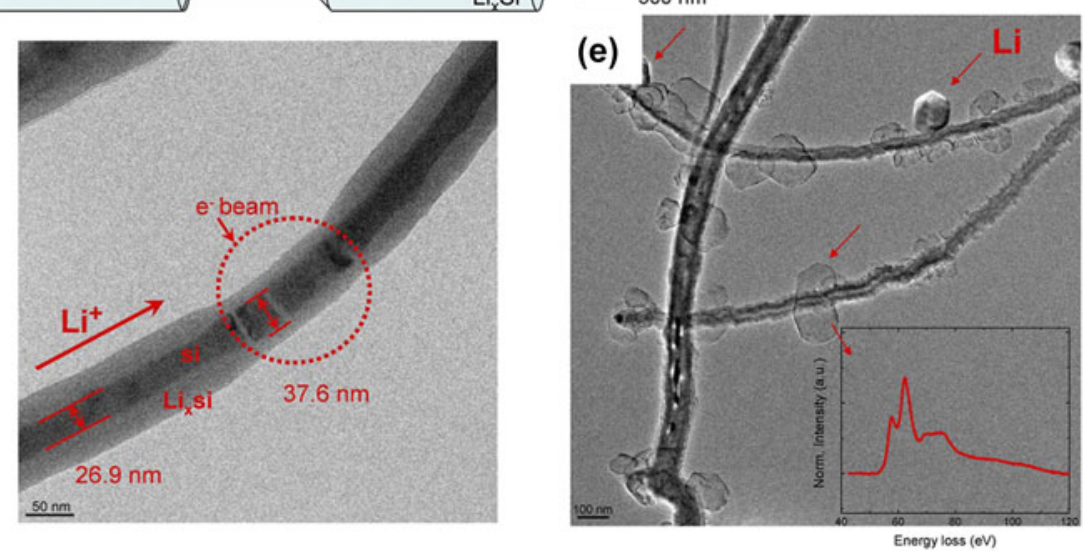

FIG. 7. (a) Schematic drawing showing the retardation of the lithiation of Si nanowire by the imaging electron. (b) TEM image showing the electron beam effect during lithiation. The imaging electron beam with an acceleration voltage of $300 \mathrm{kV}$ was focused on the region indicated by the red circle, where lithiation is retarded as indicated by a crystalline Si core width of $37.6 \mathrm{~nm}$ compared to $26.9 \mathrm{~nm}$ in the region without electron beam exposure. Using this imaging condition, the electron dose is $22.3 \mathrm{~A} / \mathrm{m}^{2}$. TEM image shows electron-beam-induced delithiation of lithiated $\mathrm{Si}$ NWs. (c) Lithiated Si NW with Si crystalline core and amorphous $\mathrm{Li}_{x} \mathrm{Si}$ lithiated region. (d) The same region in (c) is delithiated following a prolonged electron beam exposure. (e) Higher magnification TEM image showing the formation of Li metal on the surface of the delithiated Si NW. The inset shows the Li $K$ edge EELS from the Li metal.

voltage $(400 \mathrm{kV})$. Contrary to the case of $\mathrm{Si}$, Liu et al. observed that electron irradiation of $\mathrm{SnO}_{2}$ nanowire and $\mathrm{Li}_{2} \mathrm{O}$ junction on a TEM grid leads to the lithiation of $\mathrm{SnO}_{2} \cdot{ }^{109}$ They proposed that electron beam irradiation of $\mathrm{Li}_{2} \mathrm{O}$ leads to the decomposition of $\mathrm{Li}_{2} \mathrm{O}$ into elemental $\mathrm{Li}$ and volatile gas, ${ }^{110,111}$ such that $2 \mathrm{Li}_{2} \mathrm{O} \rightarrow 4 \mathrm{Li}+\mathrm{O}_{2} \uparrow$, followed by $x \mathrm{Li}+\mathrm{SnO}_{2} \rightarrow \mathrm{Li}_{x} \mathrm{SnO}_{2}$. Therefore, during in situ TEM imaging, the effect of the imaging electron beam on the electrochemical process requires careful evaluation.

\section{ELECTRON RADIOLYSIS IN TEM TO PROBE ELECTROLYTE DEGRADATION}

Electrolyte degradation in rechargeable batteries has been generally realized. However, it is difficult to directly monitor and quantify such a gradual evolution of liquid in a sealed battery. Modification of imaging electrons on the sample, or electrochemical processes in general, has been very well perceived. ${ }^{112-115}$ Often, the electronbeam-induced damage or modification has to be minimized by either adjusting the accelerating voltage, reducing the electron dose, or a combination of both. Recently, Abellan et al. pioneered the concept of using electron radiolysis in TEM and STEM to study the degradation mechanism of electrolytes, as schematically illustrated in Fig. 8. ${ }^{116}$ The electron beam itself caused the localized electrochemical reaction, enabling the observation of electrolyte breakdown in real time. Via in situ S/TEM, researchers explored the stability of five different electrolytes commonly used for Li-ion and $\mathrm{Li}-\mathrm{O}_{2}$ battery applications ${ }^{117,118}$ : lithium hexafluoroarsenate $\left(\mathrm{LiAsF}_{6}\right)^{119,120} ; \mathrm{AsF}_{6}$ salt dissolved in different organic solvents, such as 1,3-dioxolane (DOL), DMC, and a mixture of DMC and EC; lithium triflate (LiTf) in dimethyl sulfoxide (DMSO) for $\mathrm{Li}-\mathrm{O}_{2}$ batteries $^{118}$; and $\mathrm{LiPF}_{6}$ in EC:DMC for Li-ion batteries. ${ }^{117}$ When the high-energy imaging electrons $(300 \mathrm{kV})$ irradiate the solution, primary and secondary scattering occurs, generating radicals and solvated electrons. For the case of a simple salt dissolved in an aqueous solution, the electron beam essentially acts as a reducing agent, where the created radicals, such as the aqueous electrons, induce the reduction of metallic cations to grow metallic nanoparticles from the solution. ${ }^{121,122}$ In more complex solutions, such as Li battery electrolytes, the solvated electrons, $e_{\mathrm{sol}}^{-}$, and other radical species induced by the electron beam will interact through secondary chemical reactions with the salt and solvent. Figure 8 depicts an example of a likely reaction occurring between 
$e_{\mathrm{sol}}^{-}$and an electrolyte solution containing the salt $\mathrm{LiAsF}_{6}$. The overall reductive decomposition of the $\mathrm{LiAsF}_{6}$ electrolyte salt on carbonaceous anodes is reported to be $\mathrm{LiAsF}_{6}+2 \mathrm{e}^{-}+2 \mathrm{Li}^{+} \rightarrow \mathrm{AsF}_{3}+3 \mathrm{LiF}^{117,120}$ Figure 8(b) illustrates both processes with the reduction reaction of $\mathrm{AsF}_{6}{ }^{-}$by the electron-beam-induced $e_{\text {sol }}^{-}$ and the subsequent recombination of $\mathrm{F}^{-}$with $\mathrm{Li}^{+}$to form solid $\mathrm{LiF}$ molecules. The rate constant for the reaction of solvated electrons with $\mathrm{AsF}_{6}{ }^{-}$is high $\left(K_{\mathrm{e}}=9 \times 10^{9} \mathrm{M}^{-1} \mathrm{~s}^{-1}\right)$, approaching values for diffusion-controlled reactions, ${ }^{123}$ which indicates that $\mathrm{AsF}_{6}{ }^{-}$is a kinetically unstable component. Once the Lewis acid $\mathrm{AsF}_{3}$ is formed at a high rate, precipitation of $\mathrm{LiF}$ can occur by a simple combination of the $\mathrm{F}^{-}$anion with $\mathrm{Li}^{+}$cation. $\mathrm{LiF}$ is a component frequently observed on the electrode surfaces after battery cycling in electrolytes containing fluorinated salts, such as $\mathrm{LiAsF}_{6}$ or $\mathrm{LiPF}_{6}{ }^{124}$ Electrolytes containing the salt $\mathrm{LiAsF}_{6}$ show fast degradation under the electron beam, consistent with the high reactivity reported for $\mathrm{LiAsF}_{6}$. In addition, all three $\mathrm{LiAsF}_{6}$-based electrolytes displayed formation of nanoparticles as degradation products, which was expected due to the known formation of LiF particles from these electrolytes during previous tests. ${ }^{124}$ The stability of the electrolytes investigated here using in situ S/TEM correlates with electrochemical trends reported in the literature, suggesting this technique potentially could provide new insights into the reduction/degradation processes that occur during the operation of Li-ion batteries.
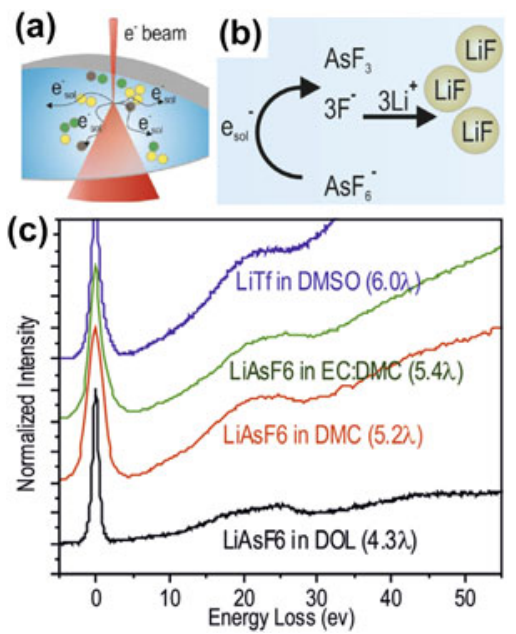

FIG. 8. (a) Schematic of the interaction of imaging electrons with liquid in the liquid-cell. (b) Example of a simple process induced by electron irradiation on an electrolyte. One-electron reduction mechanism of the $\mathrm{AsF}_{6}{ }^{-}$component in electrolytes containing the $\mathrm{LiAsF}_{6}$ salt induced by the solvated electrons followed by possible subsequent recombination with $\mathrm{Li}^{+}$into $\mathrm{LiF}$. (c) Valence band EELS of 1 molar LiTf in DMSO, $\mathrm{LiAsF}_{6}$ in EC:DMC, $\mathrm{LiAsF}_{6}$ in $\mathrm{DMC}$, and $\mathrm{LiAsF}_{6}$ in DOL. Thickness of the liquid film as a function of number of mean free paths $(\lambda)$ is given for each plot.

\section{EXTENSION OF IN SITU TEM TO IN SITU SEM}

Based on the open-cell concept using ionic liquid electrolytes, Miller et al. ${ }^{66}$ recently developed an approach for in situ observation of cathode particles during electrochemical cycling within SEM. In Fig. 9, the fundamental concept of the device is shown by the SEM image. An electrode material was partially dipped into the ionic liquid electrolyte. To monitor the electrode's internal structure under the dynamic operating conditions of the battery, a cross-section of the electrode was cut using FIB. In a typical example, $\mathrm{Li}\left(\mathrm{Ni}_{0.8} \mathrm{Co}_{0.15} \mathrm{Al}_{0.05}\right) \mathrm{O}_{2}$-based cathode materials were examined. The researchers found that significant separations develop between grains-even during the very first charge (oxide delithiation) and electrolyte penetration through that crack network all the way into the particle interior. Comparing these results to post-test microstructural characterization of oxide particles subjected to extensive cycling confirmed the occurrence of these processes in practical cells, suggesting that the physical separation and isolation of grains may contribute to performance degradation of Li-ion cells. The advantage of this cell is the large-scale observation option, which provides information on the level of electrode. The disadvantage of the device is that the ionic liquidbased electrolyte is not very relevant to the rechargeable Li-ion battery. As such, some of the electrochemical processes, such as formation of the SEI layer, may be missing.

\section{SUMMARY AND PATH FORWARD}

Both the open-cell and closed liquid-cell are feasible ways to probe structural and chemical evolution of materials for electrochemical applications, yet each method has its own associated advantages and disadvantages. The open-cell configuration offers the

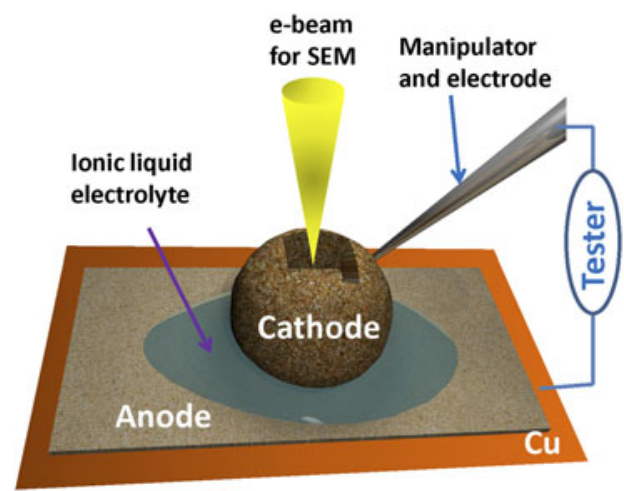

FIG. 9. Schematic drawing showing the fundamental concept of microscale battery for in situ study within FIB/SEM. A nanomanipulator probe was used to immerse or partially immerse an attached single cathode oxide particle into a liquid droplet covering an anode material. ${ }^{66}$ 
possibility of high spatial resolution imaging, but it cannot be directly correlated with electrochemical characteristics. Therefore, the open-cell is mostly suited for probing the intrinsic structural response of materials to ion insertion or extraction. Three major challenges exist for capturing high spatial resolution images using the open-cell configuration. The first one is the mechanical stability for the single nanowire system, which can be partially mitigated by using a relatively short nanowire. The second is the electronbeam-induced damage to the sample, which can be alleviated by using low-dose mode and increased detector efficiency. The third one involves orienting the sample to an appropriate zone axis as most nanomanipulators only work as a single tilt.

Development of the closed liquid-cell opens new avenues for in situ TEM study of structural and chemical evolution of electrochemical processes closely related to real working systems. Currently, for most cases, only a two-electrode system is used, and, due to the lack of the reference electrode, it often is difficult to quantitatively correlate the structural and chemical evolution with the observed electrochemical behavior. A standard three-electrode system setting for electrochemical experiments needs to be implemented. The standard electrochemical techniques, such as electrochemical impedance spectroscopy (EIS), cyclic voltammetry (CV), and chronoamperometry (CA), also need to be used. Furthermore, as a single nanowire often is used within the system, the possible involvement of peripheral material in the electrochemical process needs to be eliminated, or the surface must be passivated.

A critical contribution of the closed liquid-cell will be the observation of the SEI layers in the electrochemical system. To make this observation feasible, the following factors must be carefully considered and optimized. (1) The electron-beam-induced effects on the electrolyte need to be carefully calibrated. To eliminate possible artifacts of the electron-beam-induced electrolyte decomposition, the imaging electron dose needs to drop below the damage threshold of the electrolytes. ${ }^{125,126}$ (2) Improving the image resolution through liquid. To obtain in situ images with high spatial resolution using organic solvent electrolytes, the thickness of the liquid layer and electron dosage needs to be optimized. ${ }^{26,89,90,125-128}$ The thickness of the liquid layer usually is decided by the spacer between the top and bottom chips. However, due to the liquid-induced window bulging, the liquid cell center will be much thicker than the nominal thickness. The spatial resolution drops significantly as the thickness increases, as shown in early literature. ${ }^{26,89,90,127,128}$ The total $\mathrm{SiN}_{x}$-liquid thickness, $t$, can be estimated using EELS based on $I / I_{0}=e^{(-t / \lambda)},{ }^{129}$ where $\lambda$ is the inelastic mean free path, $I_{0}$ is the intensity of the zero-loss peak, and $I$ is total electron intensity. This method has been used to estimate the thickness of aqueous solutions within the liquid-cell. ${ }^{127}$ Based on EELS, Holtz et al. ${ }^{130}$ mapped the liquid film thickness distribution, which clearly demonstrated that the bulging of the film increased the total thickness by a factor of $2-3$. The bulging effect depends on a range of factors, such as the geometry/size of the window and film thickness. An optimized design of the window with an overall thin liquid layer ultimately will increase the image resolution. (3) The distance between the counter electrode and the working electrode needs to be shortened. In the optimized cell, the distance between the Li-source and the counter electrode should be controlled to the approximately tens of micrometer range. Thus, a more precise delivery and attachment of the Li-source electrode need to be developed within the liquid cell. One promising approach for implementing the attachment of a Li-source electrode with high accuracy is the FIB lift-out procedure. ${ }^{131}$ Although the closed liquid-cell offers the promise of mimicking real battery behavior, the in situ cell only can be cycled for a few cycles, which is far less than the several hundred to thousand cycles of a real battery. Therefore, the structural and chemical evolution of the materials captured by the in situ cell only reflects what happens at the initial stage of battery performance. Thus, rather than expecting a long life cycle study of an electrochemical system, using the in situ cell should focus primarily on exploring the fundamental process in an electrochemical cell.

\section{ACKNOWLEDGMENTS}

The author would like to thank Meng $\mathrm{Gu}$ for his contribution to part of the in situ TEM studies. Most of the in situ work was carried out with support of the Assistant Secretary for Energy Efficiency and Renewable Energy, Office of Vehicle Technologies of the U.S. Department of Energy (DOE), Contract No. DE-AC02-05CH11231, Subcontract No. 6951379, under the Batteries for Advanced Transportation Technologies (BATT) Program and from the Chemical Imaging Initiative at Pacific Northwest National Laboratory (PNNL) under the Laboratory Directed Research and Development Program. The work was performed at EMSL, a national scientific user facility sponsored by the DOE's Office of Biological and Environmental Research and located at PNNL. PNNL is multi-program national laboratory operated by Battelle for the DOE under Contract DE-AC05-76RL01830. The author thanks the help of Norman Salmon and Daan Hein Alsem of Hummingbird Scientific for developing the liquid electrochemical holder that makes part of the work possible. 


\section{REFERENCES}

1. M. Haider, S. Uhlemann, E. Schwan, H. Rose, B. Kabius, and K. Urban: Electron microscopy image enhanced. Nature 392 (6678), 768 (1998).

2. O.L. Krivanek, N. Dellby, and A.R. Lupini: Towards sub-angstrom electron beams. Ultramicroscopy 78, 1 (1999).

3. O.L. Krivanek, P.D. Nellist, N. Dellby, M.F. Murfitt, and Z. Szilagyi: Towards sub- $0.5 \AA$ Alectron beams. Ultramicroscopy 96, 229 (2003).

4. H. Mueller, S. Uhlemann, P. Hartel, and M. Haider: Advancing the hexapole Cs-corrector for the scanning transmission electron microscope. Microsc. Microanal. 12, 442 (2006).

5. P.E. Batson, N. Dellby, and O.L. Krivanek: Sub-ångstrom resolution using aberration corrected electron optics. Nature 418, 617 (2002).

6. C. Kisielowskia, B. Freitaga, M. Bischoffa, H. van Lina, S. Lazara, G. Knippelsa, P. Tiemeijera, M. van der Stama, S. von Harracha, M. Stekelenburga, M. Haidera, S. Uhlemanna, H. Müllera, P. Hartela, B. Kabiusa, D. Millera, I. Petrova, E.A. Olsona, T. Doncheva, E.A. Kenika, A.R. Lupinia, J. Bentleya, S.J. Pennycooka, I.M. Andersona, A.M. Minora, A.K. Schmida, T. Dudena, V. Radmilovica, Q.M. Ramassea, M. Watanabea, R. Ernia, E.A. Stacha, P. Denesa, and U. Dahme: Detection of single atoms and buried defects in three dimensions by aberration-corrected electron microscope with 0.5 - $\AA$ information limit. Microsc. Microanal. 14, 469 (2008).

7. H. Sawada, F. Hosokawa, T. Kaneyama, T. Ishizawa, M. Terao, M. Kawazoe, T. Sannomiya, T. Tomita, Y. Kondo, T. Tanaka, Y. Oshima, Y. Tanishiro, N. Yamamoto, and K. Takayanagi: Achieving $63 \mathrm{pm}$ resolution in scanning transmission electron microscope with spherical aberration corrector. Jpn. J. Appl. Phys. 46, L568 (2007)

8. K.W. Urban: Is science prepared for atomic resolution electron microscopy? Nat. Mater. 8, 260 (2009).

9. O.L. Krivanek, G.J. Corbin, N. Dellby, B.F. Elston, R.J. Keyse, M.F. Murfitt, C.S. Own, Z.S. Szilagyi, and J.W. Woodruff: An electron microscope for the aberration-corrected era. Ultramicroscopy 108, 179 (2007).

10. D.A. Muller, L. Fitting Kourkoutis, M.F. Murfitt, J.H. Song, H.Y. Hwang, J. Silcox, N. Dellby, and O.L. Krivanek: Atomic-scale chemical imaging of composition and bonding by aberration-corrected microscopy. Science 319, 1073 (2008).

11. D.A. Muller: Structure and bonding at the atomic scale by scanning transmission electron microscopy. Nat. Mater. 8, 263 (2009).

12. C.L. Jia, M. Lentzen, and K. Urban: Atomic-resolution imaging of oxygen in perovskite ceramics. Science 299, 870 (2003).

13. P.D. Nellist and S.J. Pennycook: Direct imaging of the atomic configuration of ultradispersed catalysts. Science 274, 413 (1996).

14. C-L. Jia, S-B. Mi, K. Urban, I. Vrejoiu, M. Alexe, and D. Hesse: Atomic-scale study of electric dipoles near charged and uncharged domain walls in ferroelectric films. Nat. Mater. 7, 57 (2008).

15. A.R. Harutyunyan, G.G. Chen, T.M. Paronyan, E.M. Pigos, O.A. Kuznetsov, K. Hewaparakrama, S.M. Kim, D. Zakharov, E.A. Stach, and G.U. Sumanasekera: Preferential growth of single-walled carbon nanotubes with metallic conductivity. Science 326, 116 (2009).

16. B.J. Kim, J. Tersoff, S. Kodambaka, M.C. Reuter, E.A. Stach, and F.M. Ross: Kinetics of individual nucleation events observed in nanoscale vapor-liquid-solid growth. Science 322, 1070 (2008).

17. P.L. Hansen, J.B. Wagner, S. Helveg, J.R. Rostrup-Nielsen, B.S. Clausen, and H. Topsoe: Atom-resolved imaging of dynamic shape changes in supported copper nanocrystals. Science 295, 2053 (2002).
18. P. Nolte, A. Stierle, N.Y. Jin-Phillipp, N. Kasper, T.U. Schulli, and H. Dosch: Shape changes of supported Rh nanoparticles during oxidation and reduction cycles. Science 321, 1654 (2008).

19. H. Yoshida, Y. Kuwauchi, J.R. Jinschek, K. Sun, S. Tanaka, M. Kohyama, S. Shimada, M. Haruta, and S. Takeda: Visualizing gas molecules interacting with supported nanoparticulate catalysts at reaction conditions. Science 335, 317 (2012).

20. Z.W. Shan, R.K. Mishra, S.A.S. Asif, O.L. Warren, and A.M. Minor: Mechanical annealing and source-limited deformation in submicrometre-diameter Ni crystals. Nat. Mater. 7, 115 (2008).

21. A.M. Minor, S.A.S. Asif, Z.W. Shan, E.A. Stach, E. Cyrankowski, T.J. Wyrobek, and O.L. Warren: A new view of the onset of plasticity during the nanoindentation of aluminium. Nat. Mater. 5, 697 (2006).

22. H.M. Zheng, R.K. Smith, Y.W. Jun, C. Kisielowski, U. Dahmen, and A.P. Alivisatos: Observation of single colloidal platinum nanocrystal growth trajectories. Science 324, 1309 (2009).

23. H.G. Liao, L.K. Cui, S. Whitelam, and H.M. Zheng: Real-time imaging of Pt3Fe nanorod growth in solution. Science 336, 1011 (2012).

24. D. Li, M.H. Nielsen, J.R.I. Lee, C. Frandsen, J.F. Banfield, and J.J. De Yoreo: Direction-specific interactions control crystal growth by oriented attachment. Science 336, 1014 (2012).

25. M.J. Williamson, R.M. Tromp, P.M. Vereecken, R. Hull, and F.M. Ross: Dynamic microscopy of nanoscale cluster growth at the solid-liquid interface. Nat. Mater. 2, 532 (2003).

26. N. de Jonge, D.B. Peckys, G.J. Kremers, and D.W. Piston: Electron microscopy of whole cells in liquid with nanometer resolution. Proc. Natl. Acad. Sci. 106, 2159 (2009).

27. B. Kang and G. Ceder: Battery materials for ultrafast charging and discharging. Nature 458, 190 (2009).

28. P. Poizot, S. Laruelle, S. Grugeon, L. Dupont, and J.M. Tarascon: Nano-sized transition-metal oxides as negative-electrode materials for lithium-ion batteries. Nature 407, 496 (2000).

29. B. Scrosati: Challenge of portable power. Nature 373, 557 (1995).

30. J.M. Tarascon and M. Armand: Issues and challenges facing rechargeable lithium batteries. Nature 414, 359 (2001).

31. M. Gu, I. Belharouak, A. Genc, Z. Wang, D. Wang, K. Amine, F. Gao, G. Zhou, S. Thevuthasan, D.R. Baer, J-G. Zhang, N.D. Browning, J. Liu, and C. Wang: Conflicting roles of nickel in controlling cathode performance in lithium ion batteries. Nano Lett. 12, 5186 (2012).

32. R. Retoux, T. Brousse, and D.M. Schleich: High-resolution electron microscopy investigation of capacity fade in $\mathrm{SnO} 2$ electrodes for lithium-ion batteries. J. Electrochem. Soc. 146, 2472 (1999).

33. C. Delmas, M. Maccario, L. Croguennec, F.L. Cras, and F. Weill: Lithium deintercalation in $\mathrm{LiFePO}_{4}$ nanoparticles via a domino-cascade model. Nat. Mater. 7, 665 (2008).

34. P. Gibot, M. Casas-Cabanas, L. Laffont, S. Levasseur, P. Carlach, S. Hamelet, J.M. Tarascon, and C. Masquelier: Room-temperature single-phase li insertion/extraction in nanoscale LixFePO ${ }_{4}$. Nat. Mater. 77, 741 (2008).

35. G.Y. Chen, X.Y. Song, and T.J. Richardson: Electron microscopy study of the $\mathrm{LiFePO}_{4}$ to $\mathrm{FePO} 4$ phase transition. Electrochem. Solid State Lett. 9, A295 (2006).

36. L. Laffont, C. Delacourt, P. Gibot, M.Y. Wu, P. Kooyman, C. Masquelier, and J. Marie Tarascon: Study of the $\mathrm{LiFePO}_{4} / \mathrm{FePO}_{4}$ two-phase system by high-resolution electron energy loss spectroscopy. Chem. Mater. 18, 5520 (2006).

37. H. Gabrisch, R. Yazami, and B. Fultz: A transmission electron microscopy study of cycled LiCoO2. J. Power Sources 119, 675 (2003). 
38. J. Graetz, C.C. Ahn, R. Yazami, and B. Fultz: An electron energy-loss spectroscopy study of charge compensation in $\mathrm{LiNi}_{0.8} \mathrm{Co}_{0.2} \mathrm{O}_{2}$. J. Phys. Chem. B 107, 2887 (2003).

39. Y.S. Meng, G. Ceder, C.P. Grey, W.S. Yoon, M. Jiang, J. Greger, and Y. Shao-Horn: Cation ordering in layered $\mathrm{O}_{3} \mathrm{Li}$ $\left[\mathrm{NixLi}_{1 / 3-2 \mathrm{x} / 3} \mathrm{Mn}_{2 / 3-\mathrm{x} / 3}\right] \mathrm{O}_{2}(0=\mathrm{x}=1 / 2)$ compounds. Chem. Mater. 17, 2386 (2005).

40. M.T. McDowell and Y. Cui: Single nanostructure electrochemical devices for studying electronic properties and structural changes in lithiated Si nanowires. Adv. Energy Mater. 7, 894 (2011)

41. S.W. Lee, M.T. McDowell, J.W. Choi, and Y. Cui: Anomalous shape changes of silicon nanopillars by electrochemical lithiation. Nano Lett. 11, 3034 (2011).

42. H. Bryngelsson, M. Stjerndahl, T. Gustafsson, and K. Edstrom: How dynamic is the SEI?. J. Power Sources 174, 970 (2007).

43. F. Kong, R. Kostecki, G. Nadeau, X. Song, K. Zaghib, K. Kinoshita, and F. McLarnon: In situ studies of SEI formation. J. Power Sources 97-98, 58 (2001).

44. H. Gabrisch, R. Yazami, and B. Fultz: Charge/discharge simulation of an all-solid-state thin-film battery using a one-dimensional model. Electrochem. Solid State Lett. 56, A111 (2002).

45. S.K. Eswaramoorthy, J.M. Howe, and G. Muralidharan: In-situ determination of the nanoscale chemistry and behavior of solidliquid systems. Science 318, 1437 (2007).

46. R. Dedryvere, H. Martinez, S. Leroy, D. Lemordant, F. Bonhomme, P. Biensan, and D. Gonbeau: Surface film formation on electrodes in a $\mathrm{LiCoO} 2 /$ graphite gell: A step by step XPS study. J. Power Sources 174, 462 (2007).

47. S.I. Nishimura, G. Kobayashi, K. Ohoyama, R. Kanno, M. Yashima, and A. Yamada: Experimental visualization of lithium diffusion in $\mathrm{LixFePO}_{4}$. Nat. Mater. 7, 707 (2008).

48. V. Mauchamp, P. Moreau, L. Moncondut, M.L. Doublet, F. Boucher, and G. Ouvrard: Determination of lithium insertion sites in LixTiP4 $(x=2-11)$ by electron energy-loss spectroscopy. J. Phys. Chem. C 111, 3996 (2007).

49. A. Brazier, L. Dupont, L. Dantras-Laffront, N. Kuwata, J. Kawamura, and J.M. Tarascon: First cross-section observation of an all solid-state lithium-ion "nanobattery" by transmission electron microscopy. Chem. Mater. 20, 2352 (2008).

50. S.F. Lux, M. Schmuck, B. Rupp, W. Kern, G.B. Appetecchi, S. Passerini, M. Winter, and A. Balducci: Mixtures of ionic liquids in combination with graphite electrodes: The role of Li-salt. ECS Trans. 16, 45 (2009).

51. A. Lewandowski and A. Świderska-Mocek: Properties of the graphite-lithium anode in $\mathrm{N}$-methyl-N-propylpiperidinium bis (trifluoromethanesulfonyl)imide as an electrolyte. J. Power Sources 171, 938 (2007).

52. K. Yamamoto, Y. Iriyama, T. Asaka, T. Hirayama, H. Fujita, C.A.J. Fisher, K. Nonaka, Y. Sugita, and Z. Ogumi: Dynamic visualization of the electric potential in an all-solid-state rechargeable lithium battery. Angew. Chem., Int. Ed. 49, 4414 (2010).

53. C.M. Wang, W. Xu, J. Liu, D.W. Choi, B. Arey, L.V. Saraf, J.G. Zhang, Z.G. Yang, S. Thevuthasan, D.R. Baer, and N. Salmon: In situ transmission electron microscopy and spectroscopy studies of interfaces in $\mathrm{Li}$ ion batteries: Challenges and opportunities. J. Mater. Res. 25, 1541 (2010).

54. C.M. Wang, W. Xu, J. Liu, J.G. Zhang, L.V. Saraf, B.W. Arey, D.W. Choi, Z.G. Yang, J. Xiao, S. Thevuthasan, and D.R. Baer: In situ transmission electron microscopy observation of microstructure and phase evolution in a $\mathrm{SnO} 2$ nanowire during lithium intercalation. Nano Lett. 11, 1874 (2011).

55. M. Klett, M. Giesecke, A. Nyman, F. Hallberg, R.W. Lindstrom, G. Lindbergh, and I. Furo: Quantifying mass transport during polarization in a li ion battery electrolyte by in situ Li-7 NMR imaging. J. Am. Chem. Soc. 134, 14654 (2012).
56. J. Wang, Y-C.K. Chen-Wiegart, and J. Wang: In situ chemical mapping of a lithium-ion battery using full-field hard $\mathrm{x}$-ray spectroscopic imaging. Chem. Commun. 49, 6480 (2013).

57. I.T. Lucas, E. Pollak, and R. Kostecki: In situ AFM studies of SEI formation at a Sn electrode. Electrochem. Commun. 11, 2157 (2009).

58. S.F. Lux, I.T. Lucas, E. Pollak, S. Passerini, M. Winter, and R. Kostecki: The mechanism of HF formation in LiPF6 based organic carbonate electrolytes. Electrochem. Commun. 14, 47 (2012).

59. P. Novak, D. Goers, L. Hardwick, M. Holzapfel, W. Scheifele, J. Ufhiel, and A. Wursig: Advanced in situ characterization methods applied to carbonaceous materials. J. Power Sources 146, 15 (2005).

60. J.Y. Huang, L. Zhong, C.M. Wang, J.P. Sullivan, W. Xu, L.Q. Zhang, S.X. Mao, N.S. Hudak, X.H. Liu, A. Subramanian, H.Y. Fan, L.A. Qi, A. Kushima, and J. Li: In situ observation of the electrochemical lithiation of a single $\mathrm{SnO}_{2}$ nanowire electrode. Science 330, 1515 (2010).

61. M.T. McDowell, I. Ryu, S.W. Lee, C. Wang, W.D. Nix, and Y. Cui: Studying the kinetics of crystalline silicon nanoparticle lithiation with in situ transmission electron microscopy. Adv. Mater. 24, 6034 (2012).

62. X.H. Liu, J.W. Wang, S. Huang, F. Fan, X. Huang, Y. Liu, S. Krylyuk, J. Yoo, S.A. Dayeh, A.V. Davydov, S.X. Mao, S.T. Picraux, S. Zhang, J. Li, T. Zhu, and J.Y. Huang: In situ atomic-scale imaging of electrochemical lithiation in silicon. Nat. Nanotechnol. 7, 749 (2012).

63. X.H. Liu, L.Q. Zhang, L. Zhong, Y. Liu, H. Zheng, J.W. Wang, J-H. Cho, S.A. Dayeh, S.T. Picraux, J.P. Sullivan, S.X. Mao, Z.Z. Ye, and J.Y. Huang: Ultrafast electrochemical lithiation of individual Si nanowire anodes. Nano Lett. 11, 2251 (2011).

64. C-M. Wang, X. Li, Z. Wang, W. Xu, J. Liu, F. Gao, L. Kovarik, J-G. Zhang, J. Howe, D.J. Burton, Z. Liu, X. Xiao, S. Thevuthasan, and D.R. Baer: In situ TEM investigation of congruent phase transition and structural evolution of nanostructured silicon/carbon anode for lithium ion batteries. Nano Lett. 12, 1624 (2012).

65. H. Ghassemi, M. Au, N. Chen, P.A. Heiden, and R.S. Yassar: In-situ electrochemical lithiation/delithiation observation of individual amorphous $\mathrm{Si}$ nanorods. ACS Nano 5, 7805 (2011).

66. D.J. Miller, C. Proff, J.G. Wen, D.P. Abraham, and J. Bareño: Observation of microstructural evolution in Li battery cathode oxide particles by in situ electron microscopy. Adv. Energy Mater. 3, 1098 (2013).

67. F. Wang, H-C. Yu, M-H. Chen, L. Wu, N. Pereira, K. Thornton, A. Van der Ven, Y. Zhu, G.G. Amatucci, and J. Graetz: Tracking lithium transport and electrochemical reactions in nanoparticles. Nat. Commun. 3, 1201 (2012).

68. Y.S. Meng, T. McGilvray, M-C. Yang, D. Gostovic, F. Wang, D. Zeng, Y. Zhu, and J. Graetz: In situ analytical electron microscopy for probing nanoscale electrochemistry. Electrochem. Soc. Interface 20, 49 (2011).

69. L.Q. Mai, Y.J. Dong, L. Xu, and C.H. Han: Single nanowire electrochemical devices. Nano Lett. 10, 4273 (2010).

70. H. Ghassemi, M. Au, N. Chen, P.A. Heiden, and R.S. Yassar: Real-time observation of lithium fibers growth inside a nanoscale lithium-ion battery. Appl. Phys. Lett. 99, 123113 (2011).

71. M. Gu, Y. Li, X. Li, S. Hu, X. Zhang, W. Xu, S. Thevuthasan, D.R. Baer, J-G. Zhang, J. Liu, and C. Wang: In situ TEM study of lithiation behavior of silicon nanoparticles attached to and embedded in a carbon matrix. ACS Nano 6, 8439 (2012). 
72. A. Nie, L-Y. Gan, Y. Cheng, H. Asayesh-Ardakani, Q. Li, C. Dong, R. Tao, F. Mashayek, H-T. Wang, U. Schwingenschlögl, R.F. Klie, and R.S. Yassar: Atomic-scale observation of lithiation reaction front in nanoscale $\mathrm{SnO}_{2}$ materials. ACS Nano 23, 6203 (2013).

73. H. Yang, S. Huang, X. Huang, F. Fan, W. Liang, X.H. Liu, L-Q. Chen, J.Y. Huang, J. Li, T. Zhu, and S. Zhang: Orientationdependent interfacial mobility governs the anisotropic swelling in lithiated silicon nanowires. Nano Lett. 12, 1953 (2012).

74. X.H. Liu, L. Zhong, S. Huang, S.X. Mao, T. Zhu, and J.Y. Huang: Size-dependent fracture of silicon nanoparticles during lithiation. ACS Nano 6, 1522 (2012).

75. X.H. Liu, S. Huang, S.T. Picraux, J. Li, T. Zhu, and J.Y. Huang: Reversible nanopore formation in Ge nanowires during lithiationdelithiation cycling: An in situ transmission electron microscopy study. Nano Lett. 11, 3991 (2011).

76. Y. Liu, N.S. Hudak, D.L. Huber, S.J. Limmer, J.P. Sullivan, and J.Y. Huang: In situ transmission electron microscopy observation of pulverization of aluminum nanowires and evolution of the thin surface $\mathrm{Al}_{2} \mathrm{O}_{3}$ layers during lithiation-delithiation cycles. Nano Lett. 11, 4188 (2011).

77. L.Q. Zhang, X.H. Liu, Y-C. Perng, J. Cho, J.P. Chang, S.X. Mao, Z.Z. Ye, and J.Y. Huang: Direct observation of Sn crystal growth during the lithiation and delithiation processes of $\mathrm{SnO}_{2}$ nanowires. Micron 43, 1127 (2012).

78. L. Zhong, X.H. Liu, G.F. Wang, S.X. Mao, and J.Y. Huang: Multiple-stripe lithiation mechanism of individual $\mathrm{SnO}_{2}$ nanowires in a flooding geometry. Phys. Rev. Lett. 106, 248302 (2011).

79. A. Kushima, X.H. Liu, G. Zhu, Z.L. Wang, J.Y. Huang, and J. Li: Leapfrog cracking and nanoamorphization of $\mathrm{ZnO}$ nanowires during in situ electrochemical lithiation. Nano Lett. 11, 4535 (2011).

80. X.H. Liu, J.W. Wang, Y. Liu, H. Zheng, A. Kushima, S. Huang, T. Zhu, S.X. Mao, J. Li, S. Zhang, W. Lu, J.M. Tour, and J.Y. Huang: In situ transmission electron microscopy of electrochemical lithiation, delithiation and deformation of individual graphene nanoribbons. Carbon 50, 3836 (2012).

81. Q.Q. Li, P. Wang, Q. Feng, M.M. Mao, J.B. Liu, S.X. Mao, and H.T. Wang: In situ TEM on the reversibility of nanosized Sn anodes during the electrochemical reaction. Chem. Mater. 26, 4102 (2014).

82. Y. Liu, H. Zheng, X.H. Liu, S. Huang, T. Zhu, J. Wang, A. Kushima, N.S. Hudak, X. Huang, S. Zhang, S.X. Mao, X. Qian, J. Li, and J.Y. Huang: Lithiation-induced embrittlement of multiwalled carbon nanotubes. ACS Nano 5, 7245 (2011).

83. M.M. Islam and T. Bredow: Density functional theory study for the stability and ionic conductivity of $\mathrm{Li}_{2} \mathrm{O}$ surfaces. J. Phys. Chem. C 113, 672 (2009).

84. X.H. Liu, H. Zheng, L. Zhong, S. Huang, K. Karki, L.Q. Zhang, Y. Liu, A. Kushima, W.T. Liang, J.W. Wang, J-H. Cho, E. Epstein, S.A. Dayeh, S.T. Picraux, T. Zhu, J. Li, J.P. Sullivan, J. Cumings, C. Wang, S.X. Mao, Z.Z. Ye, S. Zhang, and J.Y. Huang: Anisotropic swelling and fracture of silicon nanowires during lithiation. Nano Lett. 11, 3312 (2011).

85. M. Meng Gu, A. Kushima, Y. Shao, J-G. Zhang, J. Liu, N.D. Browning, J. Li, and C-M. Wang: Probing the failure mechanism of $\mathrm{SnO} 2$ nanowires for sodium-ion batteries. Nano Lett. 13, 5203-5211 (2013).

86. J.E. Evans, K.L. Jungjohann, N.D. Browning, and I. Arslan: Controlled growth of nanoparticles from solution with in situ liquid transmission electron microscopy. Nano Lett. 11, 2809 (2011).

87. L.R. Parent, D.B. Robinson, T.J. Woehl, W.D. Ristenpart, J.E. Evans, N.D. Browning, and I. Arslan: Direct in situ observation of nanoparticle synthesis in a liquid crystal surfactant template. ACS Nano 6, 3589 (2012).
88. K.L. Jungjohann, S. Bliznakov, P.W. Sutter, E.A. Stach, and E.A. Sutter: In situ liquid cell electron microscopy of the solution growth of Au-Pd core-shell nanostructures. Nano Lett. 13, 2964 (2013).

89. T.J. Woehl, J.E. Evans, I. Arslan, W.D. Ristenpart, and N.D. Browning: Direct in situ determination of the mechanisms controlling nanoparticle nucleation and growth. ACS Nano 6 , 8599 (2012).

90. N. de Jonge and F.M. Ross: Electron microscopy of specimens in liquid. Nat. Nanotechnol. 6, 695 (2011).

91. T.J. Woehl, C. Park, J.E. Evans, I. Arslan, W.D. Ristenpart, and N.D. Browning: Direct observation of aggregative nanoparticle growth: Kinetic modeling of the size distribution and growth rate. Nano Lett. 14, 373 (2013).

92. X. Chen, K.W. Noh, J.G. Wen, and S.J. Dillon: In situ electrochemical wet cell transmission electron microscopy characterization of solid-liquid interactions between $\mathrm{Ni}$ and aqueous NiCl. Acta Mater. 60, 192 (2012).

93. J.E. Evans, K.L. Jungjohann, P.C.K. Wong, P-L. Chiu, G.H. Dutrow, I. Arslan, and N.D. Browning: Visualizing macromolecular complexes with in situ liquid scanning transmission electron microscopy. Micron 43, 1085 (2012).

94. U.M. Mirsaidov, H.M. Zheng, Y. Casana, and P. Matsudaira: Imaging protein structure in water at $2.7 \mathrm{~nm}$ resolution by transmission electron microscopy. Biophys. J. 102, L15 (2012).

95. T.W. Huang, S.Y. Liu, Y.J. Chuang, H.Y. Hsieh, C.Y. Tsai, W.J. Wu, C.T. Tsai, U. Mirsaidov, P. Matsudaira, C.S. Chang, F.G. Tseng, and F.R. Chen: Dynamics of hydrogen nanobubbles in KLH protein solution studied with in situ wet-TEM. Soft Matter 9, 8856 (2013).

96. M.T. Proetto, A.M. Rush, M-P. Chien, P. Abellan Baeza, J.P. Patterson, M.P. Thompson, N.H. Olson, C.E. Moore, A.L. Rheingold, C. Andolina, J. Millstone, S.B. Howell, N.D. Browning, J.E. Evans, and N.C. Gianneschi: Dynamics of soft nanomaterials captured by transmission electron microscopy in liquid water. J. Am. Chem. Soc. 136, 1162 (2014).

97. E.R. White, S.B. Singer, V. Augustyn, W.A. Hubbard, M. Mecklenburg, B. Dunn, and B.C. Regan: In situ transmission electron microscopy of lead dendrites and lead ions in aqueous solution. ACS Nano 6, 6308 (2012).

98. H.M. Zheng, S.A. Claridge, A.M. Minor, A.P. Alivisatos, and U. Dahmen: Nanocrystal diffusion in a liquid thin film observed by in situ transmission electron microscopy. Nano Lett. 9, 2460 (2009).

99. L.R. Parent, D.B. Robinson, P.J. Cappillino, R.J. Hartnett, P. Abellán, J.E. Evans, N.D. Browning, and I. Arslan: In situ observation of directed nanoparticle aggregation during the synthesis of ordered nanoporous metal in soft templates. Chem Mater. 26, 1426 (2014).

100. M. Gu, L.R. Parent, B.L. Mehdi, R.R. Unocic, M.T. McDowell, R.L. Sacci, W. Xu, J.G. Connell, P. Xu, P. Abellan, X. Chen, Y. Zhang, D.E. Perea, J.E. Evans, L.J. Lauhon, J-G. Zhang, J. Liu, N.D. Browning, Y. Cui, I. Arslan, and C-M. Wang: Demonstration of an electrochemical liquid cell for operando transmission electron microscopy observation of the lithiation/delithiation behavior of Si nanowire battery anodes. Nano Lett. 13 6106 (2013).

101. M.E. Holtz, Y. Yu, D. Gunceler, J. Gao, R. Sundararaman, K.A. Schwarz, T.A. Arias, H.D. Abruña, and D.A. Muller: Nanoscale imaging of lithium ion distribution during in situ operation of battery electrode and electrolyte. Nano Lett. 14, 1453 (2014). 
102. R.L. Sacci, N.J. Dudney, K.L. More, L.R. Parent, I. Arslan, N.D. Browning, and R.R. Unocic: Direct visualization of initial SEI morphology and growth kinetics during lithium deposition by in situ electrochemical transmission electron microscopy. Chem. Commun. 50, 2104 (2014).

103. Z. Zeng, W-I. Liang, H-G. Liao, H.L. Xin, Y-H. Chu, and $\mathrm{H}$. Zheng: Visualization of electrode-electrolyte interfaces in LiPF6/EC/DEC electrolyte for lithium ion batteries via in situ TEM. Nano Lett. 14, 1745 (2014).

104. R.R. Unocic, R.L. Sacci, G.M. Brown, G.M. Veith, N.J. Dudney, K.L. More, F.S. Walden, II., D.S. Gardiner, J. Damiano, and D.P. Nackashi: Quantitative electrochemical measurements using in situ ec-S/TEM devices. Microsc. Microanal. 20, 452 (2014).

105. X.H. Liu, F. Fan, H. Yang, S. Zhang, J.Y. Huang, and T. Zhu: Self-limiting lithiation in silicon nanowires. ACS Nano 7, 1495 (2012).

106. Y. Yang, C. Xie, R. Ruffo, H. Peng, D.K. Kim, and Y. Cui: Single nanorod devices for battery diagnostics: A case study on $\mathrm{LiMn}_{2} \mathrm{O}_{4}$. Nano Lett. 9, 4109 (2009).

107. F. Lin, D. Nordlund, T-C. Weng, Y. Zhu, C. Ban, R.M. Richards, and H.L. Xin: Phase evolution for conversion reaction electrodes in lithium-ion batteries. Nat. Commun. 5, 3358 (2014).

108. F. Wang, J. Graetz, M.S. Moreno, C. Ma, L. Wu, V. Volkov, and Y. Zhu: Chemical distribution and bonding of lithium in intercalated graphite: Identification with optimized electron energy loss spectroscopy. ACS Nano 5, 1190 (2011).

109. X.H. Liu, Y. Liu, A. Kushima, S. Zhang, T. Zhu, J. Li, and J.Y. Huang: In situ TEM experiments of electrochemical lithiation and delithiation of individual nanostructures. Adv. Energy Mater. 2, 722 (2012).

110. P. Vajda and F. Beuneu: Electron radiation damage and Li-colloid creation in $\mathrm{Li}_{2}$ O. Phys. Rev. B 53, 5335 (1996).

111. G. Krexner, M. Prem, F. Beuneu, and P. Vajda: Nanocluster formation in electron-irradiated $\mathrm{Li}_{2} \mathrm{O}$ crystals observed by elastic diffuse neutron scattering. Phys. Rev. Lett. 91, 135502 (2003).

112. C.M. Wang, D.R. Baer, J.E. Amonettea, M.H. Engelharda, J.J. Antony, and Y. Qiang: Electron beam-induced thickening of the protective oxide layer around Fe nanoparticles. Ultramicroscopy 108, 43 (2007).

113. F. Wang, M. Malac, and R.F. Egerton: Energy-loss near-edge fine structures of iron nanoparticles. Micron 37, 316 (2006).

114. M. den Heijer, I. Shao, A. Radisic, M.C. Reuter, and F.M. Ross: Patterned electrochemical deposition of copper using an electron beam. APL Mater. 2, 022101 (2014).

115. J.M. Grogan, N.M. Schneider, F.M. Ross, and H.H. Bau: Bubble and pattern formation in liquid induced by an electron beam. Nano Lett. 14, 359 (2014).

116. P. Abellan, B.L. Mehdi, L.R. Parent, M. Gu, C. Park, W. Xu, Y. Zhang, I. Arslan, J-G. Zhang, C-M. Wang, J.E. Evans, and N.D. Browning: Probing the degradation mechanisms in electrolyte solutions for Li-ion batteries by in situ transmission electron microscopy. Nano Lett. 14, 1293 (2014).

117. K. Xu: Nonaqueous liquid electrolytes for lithium-based rechargeable batteries. Chem. Rev. 104(10), 4303 (2004).

118. E. Nasybulin, W. Xu, M.H. Engelhard, Z.M. Nie, S.D. Burton, L. Cosimbescu, M.E. Gross, and J.G. Zhang: Effects of electrolyte salts on the performance of $\mathrm{Li}^{-} \mathrm{O}_{2}$ batteries. J. Phys. Chem. C 117, 2635 (2013).

119. Y. Gofer, M. Ben-Zion, and D. Aurbach: Solutions of $\mathrm{LiAsF}_{6}$ in 1,3-dioxolane for secondary lithium batteries. J. Power Sources 39, 163 (1992)

120. C. Nanjundiah, J.L. Goldman, L.A. Dominey, and V.R. Koch: Electrochemical stability of $\mathrm{LiMF}_{6}(\mathrm{M}=\mathrm{P}, \mathrm{As}, \mathrm{Sb})$ in tetrahydrofuran and sulfolane. J. Electrochem. Soc. 135, 2914 (1988).

121. J. Belloni, M. Mostafavi, H. Remita, J.L. Marignier, and M.O. Delcourt: Radiation-induced synthesis of mono- and multi-metallic clusters and nanocolloids. New J. Chem. 22, 1239 (1998).

122. J. Belloni: Nucleation, growth and properties of nanoclusters studied by radiation chemistry - Application to catalysis. Catal. Today 113, 141 (2006).

123. E. Peled, D. Golodnitsky, C. Menachem, and D. Bar-Tow: An advanced tool for the selection of electrolyte components for rechargeable lithium batteries. J. Electrochem. Soc. 145, 3482 (1998).

124. P. Verma, P. Maire, and P. Novak: A review of the features and analyses of the solid electrolyte interphase in Li-ion batteries. Electrochim. Acta 55, 6332 (2010).

125. R.F. Egerton: Control of radiation damage in the TEM. Ultramicroscopy 127, 100 (2013).

126. T.J. Woehl, K.L. Jungjohann, J.E. Evans, I. Arslan, W.D. Ristenpart, and N.D. Browning: Experimental procedures to mitigate electron beam induced artifacts during in situ fluid imaging of nanomaterials. Ultramicroscopy 127, 53 (2013).

127. K.L. Jungjohann, J.E. Evans, J.A. Aguiar, I. Arslan, and N.D. Browning: Atomic-scale imaging and spectroscopy for in situ liquid scanning transmission electron microscopy. Microsc. Microanal. 18, 621 (2012).

128. D.A. Welch, R. Faller, J.E. Evans, and N.D. Browning: Simulating realistic imaging conditions for in situ liquid microscopy. Ultramicroscopy 135, 36 (2013).

129. R.F. Egerton: Electron Energy-Loss Spectroscopy in the Electron Microscope, 3rd ed. (Springer, New York, NY, 2011).

130. M.E. Holtz, Y. Yu, J. Gao, H.D. Abruña, and D.A. Muller: In situ electron energy-loss spectroscopy in liquids. Microsc. Microanal. 19, 1027 (2013).

131. F.A. Stevie, R.B. Irwin, T.L. Shofner, S.R. Brown, J.L. Drown, and L.A. Giannuzzi: Plan view TEM sample preparation using the focused ion beam lift-out technique. AIP Conf. Proc. 449, 868 (1998). 